\title{
Association of Alcohol Intake and Fracture Risk in Elderly Varied by Affected Bones: A Nationwide Longitudinal Study
}

\author{
Sheng-Min Wang1, Kyung-Do Han², Nak-Young Kim¹, Yoo Hyun Um³, \\ Dong Woo Kang ${ }^{4}$, Hae-Ran Na', Chang Uk Lee ${ }^{4}$, and Hyun Kook Lim ${ }^{1} \bowtie$ \\ 1'Department of Psychiatry, Yeouido St. Mary's Hospital, College of Medicine, The Catholic University of Korea, Seoul, Republic of Korea \\ ${ }^{2}$ Department of Statistics and Actuarial Science, Soongsil University, Seoul, Republic of Korea \\ ${ }^{3}$ Department of Psychiatry, St. Vincent Hospital, College of Medicine, The Catholic University of Korea, Suwon, Republic of Korea \\ ${ }^{4}$ Department of Psychiatry, Seoul St. Mary's Hospital, College of Medicine, The Catholic University of Korea, Seoul, Republic of Korea
}

Objective Previous studies investigating association of alcohol intake and fracture risk in elderly yielded conflicting results. We first examined the association between alcohol intake and total fracture risk in elderly subjects and further analyzed whether the association varied by fracture locations.

Methods This is a nationwide population-based cohort study which included all people aged $66(\mathrm{n}=1,431,539)$ receiving the National Screening Program during 2009-2014. Time-to-event were defined as duration from study recruitment, the day they received health screening, to the occurrence of fracture.

Results Total fracture was significantly lower in mild drinkers [adjusted hazard ratio (aHR) $=0.952 ; 95 \%$ confidence interval ( $95 \%$ CI) $=0.931-0.973]$ and higher in heavy drinkers $(\mathrm{aHR}=1.246$; $95 \% \mathrm{CI}=1.201-1.294)$ than non-drinkers. Risk pattern of alcohol consumption and fracture differed according to affected bones. Similar J-shaped trends were observed for vertebra fractures, but risk of limb fracture showed a linear relationship with alcohol intake. For hip fracture, risk decrement was more pronounced in mild and moderate drinkers, and significant increment was noted only in very severe drinkers [ $\geq 60 \mathrm{~g} / \mathrm{day}$; (aHR)=1.446; 1.162-1.801].

Conclusion Light to moderate drinking generally lowered risk of fractures, but association between alcohol and fracture risk varied depending on the affected bone lesions.

Psychiatry Investig 2020;17(10):1013-1020

Key Words Geriatric psychiatry, Addictive disorder, Community psychiatry, Epidemiology.

\section{INTRODUCTION}

Fracture in elderly is a common and an important public health issue which contributes to high burden to healthcare services. ${ }^{1}$ With population of elderly people growing, incidence of economic burden from fracture is also increasing worldwide. South Korea (hereafter "Korea") is one of the fastest aging countries in the world, and its aging index is estimated to increase to $213.8 \%$ by $2030 .^{2}$ Accordingly, economic burden of fracture in Koreans older than 65 years has already increased

Received: April 20, 2020 Revised: August 9, 2020

Accepted: August 20, 2020

$\triangle$ Correspondence: Hyun Kook Lim, MD, PhD

Department of Psychiatry, Yeouido St. Mary's Hospital, College of Medicine, The Catholic University of Korea, 10, 63-ro, Yeongdeungpo-gu, Seoul 07345, Republic of Korea

Tel: +82-2-3779-1048, Fax: +82-2-780-6577, E-mail: drblues@catholic.ac.kr (a) This is an Open Access article distributed under the terms of the Creative Commons Attribution Non-Commercial License (https://creativecommons.org/licenses/bync/4.0) which permits unrestricted non-commercial use, distribution, and reproduction in any medium, provided the original work is properly cited. from US $\$ 88.8$ million in 2007 to US $\$ 149.3$ million in $2011 .^{3}$

Excessive alcohol intake is an important risk factor of fracture. ${ }^{4}$ Numerous cohort studies acknowledged that mild to moderate drinking does not increase, in fact decreases, risk of fracture, whereas heavy consumption is associated with greater fracture incidence. ${ }^{5,6} \mathrm{~A}$ meta-analysis consisted of more than 3,700,000 participants also showed that relationship between alcohol consumption and hip fracture is non-linear with the light alcohol drinkers having the lowest risk. ${ }^{7}$ However, studies also demonstrated that the risk factor of fracture varies with age. ${ }^{8,9}$ Likewise, literature on the association of alcohol intake and fracture risk in elderly population is more diverse and complicated. In the Framingham study, moderate and heavy drinking were associated with a substantial risk of fracture in those aged less than 65 years, but there was only a marginal and nonsignificant increased risk in those aged 65 years or more. ${ }^{10}$ In elderly group, the impact of alcohol in fracture incidence also differed depending on the affected bones. Greater alcohol in- 
take was not associated with greater risk for non-spine fractures, ${ }^{11}$ whereas the risk increment was more evident for vertebral fractures. ${ }^{12}$ In addition, a prospective study showed that alcohol intake had a U-shaped relationship with risk of hip fracture. ${ }^{13}$

Despite contradictory association between alcohol intake and incidence of fracture in the elderly, all well sized cohort studies included subjects from various age groups. ${ }^{6,14}$ In studies conducted in elderly population only, none of previous researches contained more than 150,000 subjects. ${ }^{15-17}$ Moreover, all studies investigated impact of alcohol in limited number of bones, and none investigated whether the fracture risk differed depending on the skeletal lesions. To fill in this gap, we first aimed to examine the association of alcohol intake and risk of all fractures in elderly subjects using a large nationwide study from health insurance claims data. We further analyzed whether the association varied by fracture location.

\section{METHODS}

\section{Data source}

The Korean National Health Insurance Service (KNHIS) (http://nhis.or.kr/static/html/wbd/g/a/wbdga0101.html) is a mandatory public health insurance system, and it provides universal coverage to all residents Korea. All Koreans who are 40 or older were required, by KNHIS, to receive a compulsory health screening test every two years. The National Health Insurance Service-Health Screening Cohort (NHIS-HEALS) is a cohort who participated in this health screening programs. An additional health screening named National Screening Program for Transitional Ages (NSPTA) was initiated in 2007 for those aged 40 and 66 because they are regarded as transition to middle age and elderly respectively. ${ }^{18}$ All these data are systematically stored and organized by National Health Information Database, which consists of healthcare data including health screening data, sociodemographic variables, and mortality for the whole Korean population https://nhiss.nhis. or.kr/bd/ab/bdaba000eng.do. Numerous epidemiological studies using this database has been published, and its detail description can be found elsewhere. ${ }^{2,19,20}$

\section{Study population}

We first included all subjects aged 66 who participated in the NSPTA program during 2009-2014 ( $\mathrm{n}=1,555,103)$. Thereafter, 96,847 participants having either incomplete or missing data were excluded. A one-year lag was utilized, so those who developed fracture or died within one from the health screening day were excluded $(n=26,717)$. Finally, a total of $1,431,539$ participants were included in our study (Figure 1), and their mean duration of follow-up was $3.52 \pm 1.76$ (maximum of 7)

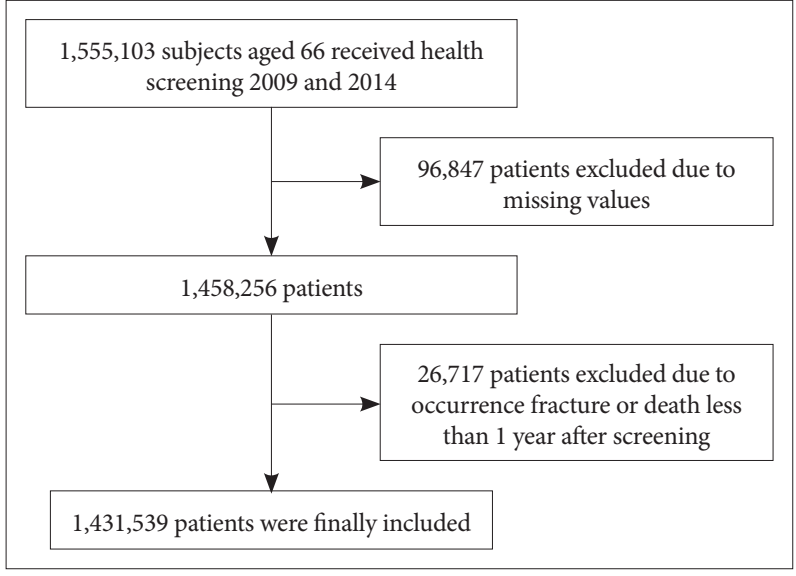

Figure 1. Flow chart depicting creation of study cohorts.

years. Information regarding health-related lifestyle, medical history, basic physical data (including body mass index and blood pressure), and clinical tests results are included in the questionnaire obtained during the mandatory health screening. This study was approved by the Institutional Review Board of Yeouido St. Mary's Hospital, Seoul, Korea (No. SC19ZESI0124). Consent from individual subjects were not needed because the study used publicly open, anonymous data.

\section{Exposure variable - alcohol consumption}

Frequency and amount of alcohol consumption was based on questionnaire reports. All participants first responded to a close-ended question regarding frequency of alcohol consumption: "In average, how often do you drink alcohol per week?" They were instructed to choose a specific number ranging from 0 (none)-7 (7 days/week). In terms of amount of alcohol consumption, participants were then asked an open-ended question: "When you consume alcohol, how many drinks do you usually consume per day?" They were instructed to count amount of alcohol consumption to "drinks/day" regardless of alcohol type with a following detailed description: "a can of beer $(355 \mathrm{cc}$ ) is equivalent to 1.6 drinks."

Based on these reports, we quantified their alcohol intake to grams/day. The interpretation of a standard drink can vary from country to country, and we used the most conservative definition and calculated 1 standard drink to 8 grams of ethanol..$^{21}$ Thereafter, we calculated participants daily alcohol intake [(drinks/day $\times$ days/week $\times 8 \mathrm{~g} /$ drinks $) / 7$ days], and the participants were divided in to four groups: not drinkers (none), mild ( $<15 \mathrm{~g} /$ day), moderate ( $<30 \mathrm{~g} /$ day), and heavy drinkers ( $\geq 30 \mathrm{~g} /$ day).

\section{Outcome variable-fractures}

Participants having ICD-10 codes for vertebral fracture (S22.0, S22.1, S32.0, M48.4, and M48.5) and visited hospital 
more than twice due to same codes were defined as having vertebral fracture. Likewise, those having ICD-10 codes and visited hospital more than twice with fracture of upper arm (S42.0, S42.2, and S42.3), forearm (S52.5 and S52.6), or lower leg (S82.3, S82.5, and S82.6) were classified as having a limb fracture. Almost all elderly with hip fracture require either surgical treatment or supportive care via hospital admission. Thus, hip fracture was defined as having ICD-10 codes of and hospitalized to a hospital due to hip fracture (S72.0 and S72.1). Finally, total fracture included fractures of vertebra, limbs, hip, and others not listed above (i.e. S02.X for skull fracture, S12. X for neck fracture, S62.X for hand, S92.X for foot).

\section{Statistical analysis}

Difference between the 4 groups in baseline demographic and clinical characteristics were compared using analysis of variance (ANOVA) for continuous variables and Chi-squared test for categorical variables. The cohorts were followed from the day they received the health screening, to the occurrence of death, or the last follow-up day (December 31, 2016), whichever came first. Time-to-event were defined as the duration from study recruitment, the day they received health screening, to the occurrence of fracture. We performed Cox proportionalhazard regression, with none drinkers as reference category, to evaluate risk of total fracture. In addition, Cox proportional-hazard regression for fracture of vertebral, hip, and limbs were conducted to assess whether the association between alcohol consumption and fracture risk differed depending on the affected or fracture lesions. The cox proportional-hazard model was adjusted for potential confounding variables known to predict risk of fracture, which included gender, income, diabetes, hypertension, hyperlipidemia, smoking, physical exercise body mass index, and fracture history. ${ }^{1,22,23}$ For all statistical analysis, we used SAS version 9.3 (SAS Institute, Cary, North Carolina, USA) with p-values $<0.05$ considered significant.

\section{RESULTS}

\section{Participant characteristics}

Among 1,431,539 participants, the number of subjects for none, mild, moderate, and heavy drinking groups were 1,027,575 (71.8\%), 247,669 (17.3\%), 88,643 (6.2\%), and 67,652 (4.7\%) respectively. The four groups did not differ in age because they were all enrolled at age of 66 . Frequency and amount of alcohol intake increased sequentially from none to heave drinking group illustrating that the participants were properly allocated based on their drinking habits and intensity. Male ratio was lowest in none group and highest in heavy drinking group. Diabetes, hypertension, weight, height, triglyceride level, smokers, waist circumference, and blood pressure were higher in moderate $\sim$ heavy drinking groups than none $\sim$ low drinking groups. In contrast, rate of hyperlipidemia decreased sequentially from none to heave drinking group. History of fall was also more prevalent in none drinking group than other drinking groups. Lastly, a reversed-U shape was observed between physical activity and drinking groups (Table 1).

\section{Group differences in fracture risk}

In cox regression, compared with non-drinkers, total fracture was significantly lower in the mild drinking group [adjusted hazard ratio $(\mathrm{aHR})=0.952 ; 95 \%$ confidence interval $(95 \%$ $\mathrm{CI})=0.931-0.973$ ] and higher in the heavy drinking group (aHR=1.246; 95\% CI=1.201-1.294). In terms of specific fractures, similar trends were observed for vertebra. However, the risk of hip fracture decreased in both mild ( $\mathrm{aHR}=0.787 ; 0.72-$ 0.86 ) and moderate ( $\mathrm{aHR}=0.773 ; 0.675-0.884)$ drinking groups, and the significance was not found in heavy $(\mathrm{aHR}=1.112 ; 0.979-$ 1.262) drinking group. Lastly, risk of limb fracture showed a linear relationship with alcohol intake (Figure 2).

\section{Fracture risk according to frequency of alcohol intake}

In terms of total fracture, we found a $21.9 \%$ (aHR=1.219; 1.177-1.263) increased risk in those drinking more than or equal to 5 times/week compared to none drinking group. In addition, the fracture risk significantly declined in those drinking less than 3 times/week ( $\mathrm{aHR}=0.944 ; 0.922-0.965)$. This Jshaped association between frequency of alcohol intake and fracture risk were also noted for vertebra. The risk decrement from mild moderate drinking was more pronounced for hip fracture (24\% for drinking less than 3 times/week and $6 \%$ for drinking 3-4 times/week). In contrast, the risk of fracture heightened linearly as frequency of drinking increased $(\mathrm{aHR}=1.116$; 1.062-1.174 for those drinking 3-4 times/week and $(\mathrm{aHR}=$ 1.253 ; 1.187-1.322 for drinking 3-4 times/week) (Table 2).

\section{Fracture risk according to amount of alcohol intake}

Once again, a J-shaped association was observed for daily alcohol intake and risk of total fracture. The risk became higher from those drinking $\geq 30 \mathrm{~g} /$ day $(\mathrm{aHR}=1.15 ; 1.076-1.229$ ), and we found a $47.5 \%$ increased risk in those drinking $\geq 60$ g/day. Similar trend was observed for vertebral fractures. The risk decrement was more pronounced for hip fractures, and the significant increase was only observed for those drinking $\geq 60 \mathrm{~g} /$ day $(\mathrm{aHR}=1.446 ; 1.162-1.801)$. The risk of limb fracture increased linearly with amount of alcohol intake, and there was $54.1 \%$ increment for those drinking $\geq 60 \mathrm{~g} /$ day (Figure 3). 
Table 1. Baseline characteristics of patients who received mandatory public health screening at age of 66

\begin{tabular}{|c|c|c|c|c|c|}
\hline & \multicolumn{5}{|c|}{ Groups according to drinking severity } \\
\hline & None & Mild & Moderate & Heavy & $\mathrm{p}$ \\
\hline Number & $1,027,575$ & 247,669 & 88,643 & 67,652 & \\
\hline Person-years & $3,618,682.12$ & $865,544.39$ & $310,740.01$ & $241,259.04$ & \\
\hline Age & $66 \pm 0$ & $66 \pm 0$ & $66 \pm 0$ & $66 \pm 0$ & \\
\hline Gender (male, \%) & $316,389(30.79)$ & $194,705(78.62)$ & $83,694(94.42)$ & $65,681(97.09)$ & $<0.0001$ \\
\hline \multicolumn{6}{|l|}{ Alcohol intake } \\
\hline Days/week & & & & & $<0.0001$ \\
\hline None & $1,027,575(100)$ & - & - & - & \\
\hline$<3$ & - & $200,452(80.94)$ & $29,166(32.9)$ & $3,586(5.3)$ & \\
\hline $3-4$ & - & $39,371(15.9)$ & $38,861(43.84)$ & $17,753(26.24)$ & \\
\hline$\geq 5$ & - & $7,846(3.17)$ & $20,616(23.26)$ & $46,313(68.46)$ & \\
\hline Grams/day & & & & & $<0.0001$ \\
\hline None & $1,027,575(100)$ & - & - & - & \\
\hline$<10$ & - & $199,605(80.59)$ & - & - & \\
\hline$>10$ & - & $48,064(19.41)$ & $42,440(47.88)$ & - & \\
\hline$>20$ & - & - & $46,203(52.12)$ & - & \\
\hline$>30$ & - & - & - & $20,041(29.62)$ & \\
\hline$>40$ & - & - & - & 19,805 (29.27) & \\
\hline$>50$ & - & - & - & 13,509 (19.97) & \\
\hline$\geq 60$ & - & - & - & $14,297(21.13)$ & \\
\hline Income_low & $288,145(28.04)$ & $74,824(30.21)$ & $27,673(31.22)$ & $19,236(28.43)$ & $<0.0001$ \\
\hline Smoking & & & & & $<0.0001$ \\
\hline None & $839,346(81.68)$ & $112,248(45.32)$ & $26,308(29.68)$ & $18,571(27.45)$ & \\
\hline Ex-smoker & $111,094(10.81)$ & $84,290(34.03)$ & $33,392(37.67)$ & $23,556(34.82)$ & \\
\hline Current & $77,135(7.51)$ & $51,131(20.64)$ & $28,943(32.65)$ & $25,525(37.73)$ & \\
\hline PA_regular & $443,814(43.19)$ & $148,894(60.12)$ & $49,577(55.93)$ & $32,501(48.04)$ & $<0.0001$ \\
\hline \multicolumn{6}{|l|}{ GDS } \\
\hline Loss of interest & $179,926(17.51)$ & $35,911(14.5)$ & $12,481(14.08)$ & $10,607(15.68)$ & $<0.0001$ \\
\hline Worthelessness & 84,757 (8.25) & $15,551(6.28)$ & $5,356(6.04)$ & 4,797 (7.09) & $<0.0001$ \\
\hline Hopelessness & $90,713(8.83)$ & $17,510(7.07)$ & $6,053(6.83)$ & 5,268 (7.79) & $<0.0001$ \\
\hline Fall (yes)* & $77,276(7.52)$ & $14,491(5.85)$ & $4,591(5.18)$ & $3,956(5.85)$ & $<0.0001$ \\
\hline Diabetes (yes) & $204,801(19.93)$ & $48,636(19.64)$ & $20,570(23.21)$ & $16,841(24.89)$ & $<0.0001$ \\
\hline Hypertension (yes) & $539,275(52.48)$ & $134,372(54.25)$ & $53,024(59.82)$ & $41,173(60.86)$ & $<0.0001$ \\
\hline Hyperlipidemia (yes) & $413,838(40.27)$ & $82,488(33.31)$ & $27,423(30.94)$ & $18,940(28)$ & $<0.0001$ \\
\hline Weight (kg) & $60.2 \pm 9.3$ & $64.54 \pm 9.24$ & $66.28 \pm 9.21$ & $66.08 \pm 9.48$ & $<0.0001$ \\
\hline Height (cm) & $157.1 \pm 7.88$ & $163.35 \pm 7.62$ & $165.38 \pm 6.26$ & $165.64 \pm 5.98$ & $<0.0001$ \\
\hline BMI $\left(\mathrm{kg} / \mathrm{m}^{2}\right)$ & $24.36 \pm 3.1$ & $24.15 \pm 2.83$ & $24.2 \pm 2.85$ & $24.05 \pm 2.96$ & $<0.0001$ \\
\hline Waist circ & $82.38 \pm 8.31$ & $84.33 \pm 7.78$ & $85.64 \pm 7.74$ & $85.82 \pm 7.95$ & $<0.0001$ \\
\hline Systolic BP & $127.54 \pm 15.21$ & $128.39 \pm 14.87$ & $130.48 \pm 15$ & $131.64 \pm 15.47$ & $<0.0001$ \\
\hline Diastolic BP & $77.2 \pm 9.64$ & $78.22 \pm 9.6$ & $79.26 \pm 9.59$ & $79.75 \pm 9.78$ & $<0.0001$ \\
\hline TG (in log value) & $117.26(117.15-117.37)$ & $116.7(116.46-116.93)$ & $126.82(126.38-127.26)$ & $132.56(132.01-133.11)$ & $<0.0001$ \\
\hline
\end{tabular}

*history of fall in the past 6 months. BMI: body mass index, BP: blood pressure, circ: circumference, GDS: Geriatric Depression Scale, TG: triglyceride, PA: physical activity, SD: standard drinks 

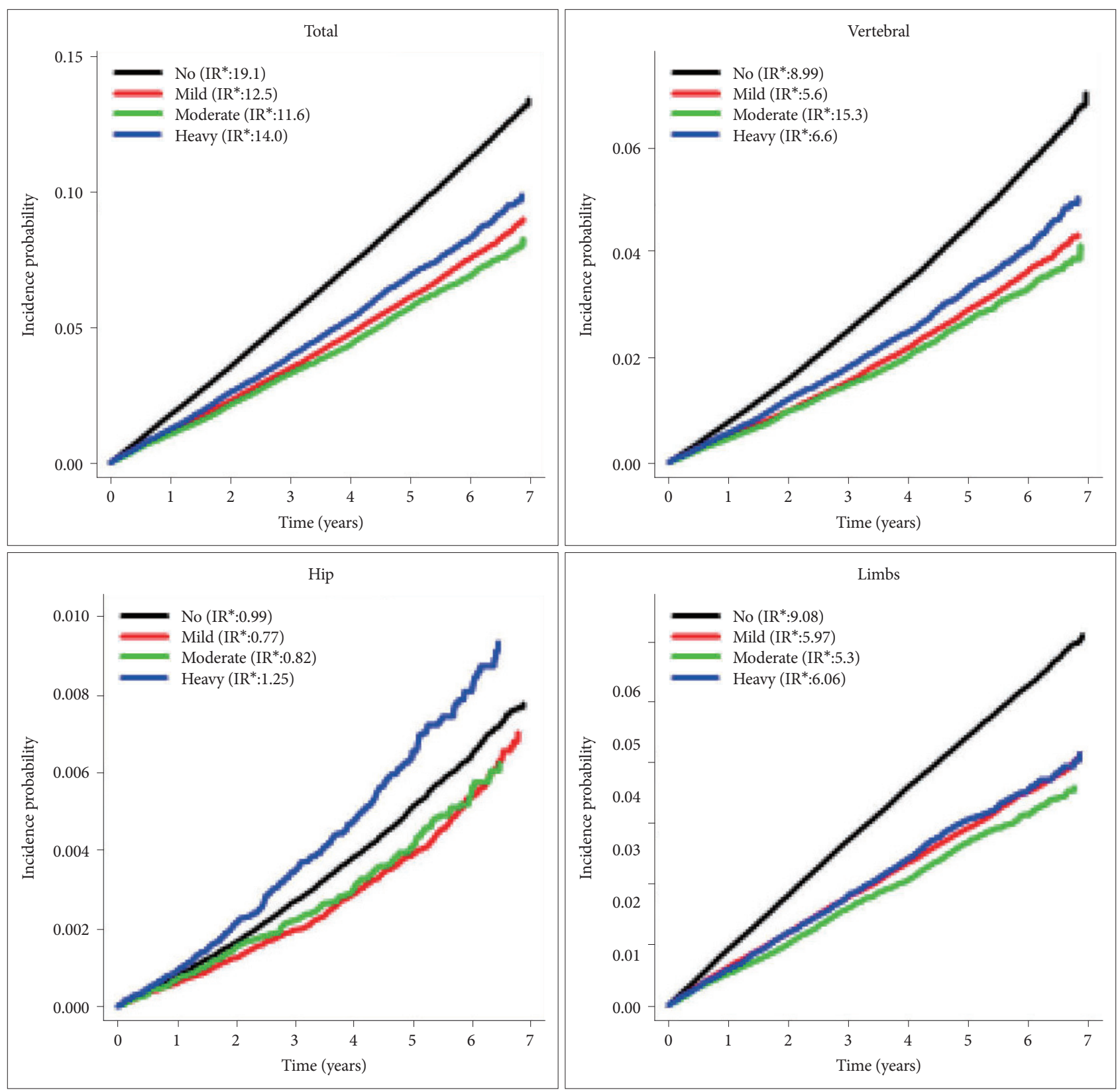

Figure 2. Risk of fractures according to groups. *Incidence rate per 1,000 years.

\section{DISCUSSION}

To the best of our knowledge, this is the largest nationwide cohort study investigating association between alcohol consumption and risk of fracture in elderly population. As expected, male ratio was lowest in none drinking group and highest in heavy drinking group. Chronic medical conditions (i.e., diabetes, hypertension, smoking, and others) related with metabolic syndrome were also higher in moderate to heavy drinking groups than none to low drinking groups, which corresponds with previous researches. ${ }^{24-27}$ However, rate of hyperlipidemia decreased sequentially from none to heave drinking group.
Increased hepatic secretion of very-low-density lipoprotein and impairment in the removal of triacylglycerol-rich lipoproteins from plasma are two important mechanisms of alcoholic hyperlipidemia, where former plays more major role. ${ }^{28}$ With more chronic and intense alcohol intake, the hyperlipemia tends to disappear because of enhanced lipolytic activity and aggravation of liver injury. ${ }^{29}$ Thus, inverse relationship between hyperlipidemia and alcohol intake might indirectly suggest that participants were properly allocated based on their drinking habits and intensity.

In terms of association between alcohol and total fracture, we first replicated previous findings and confirmed that the 
Table 2. Risk of fractures according to frequency of alcohol intake

\begin{tabular}{|c|c|c|c|c|c|c|c|c|}
\hline \multirow{2}{*}{$\begin{array}{c}\text { Alcohol } \\
\text { intake } \\
\text { (days/week) }\end{array}$} & \multirow{2}{*}{ Number } & \multirow{2}{*}{ Event } & \multirow{2}{*}{ Duration* } & \multirow{2}{*}{$\mathrm{IR}^{\dagger}$} & \multicolumn{4}{|c|}{ HR $(95 \%$ CI $)$} \\
\hline & & & & & Model 1 & Model 2 & Model 3 & Model 4 \\
\hline \multicolumn{9}{|c|}{ Total fractures } \\
\hline None & $1,027,575$ & 69,444 & $3,618,682.12$ & 19.1904 & 1 (ref.) & 1 (ref.) & 1 (ref.) & 1 (ref.) \\
\hline$<3$ & 233,204 & 10,029 & $813,626.75$ & 12.3263 & $0.643(0.63,0.657)$ & $0.931(0.911,0.953)$ & $0.942(0.921,0.964)$ & $0.944(0.922,0.965)$ \\
\hline $3-4$ & 95,985 & 3,968 & $336,810.4$ & 11.7811 & $0.615(0.596,0.635)$ & $1.009(0.975,1.044)$ & $1.004(0.97,1.039)$ & $1.009(0.975,1.044)$ \\
\hline$\geq 5$ & 74,775 & 3,788 & $267,106.28$ & 14.1816 & $0.738(0.714,0.763)$ & $1.239(1.197,1.283)$ & $1.203(1.162,1.246)$ & $1.219(1.177,1.263)$ \\
\hline \multicolumn{9}{|c|}{ Vertebral fracture } \\
\hline None & $1,027,575$ & 32,497 & $3,618,682.12$ & 8.98034 & 1 (ref.) & 1 (ref.) & 1 (ref.) & 1 (ref.) \\
\hline$<3$ & 233,204 & 4,514 & $813,626.75$ & 5.548 & $0.619(0.6,0.638)$ & $0.877(0.849,0.907)$ & $0.89(0.861,0.92)$ & $0.891(0.862,0.922)$ \\
\hline $3-4$ & 95,985 & 1,792 & $336,810.4$ & 5.3205 & $0.593(0.565,0.622)$ & $0.944(0.898,0.993)$ & $0.938(0.892,0.987)$ & $0.943(0.896,0.992)$ \\
\hline$\geq 5$ & 74,775 & 1,818 & $267,106.28$ & 6.80628 & $0.756(0.721,0.793)$ & $1.229(1.168,1.292)$ & $1.182(1.123,1.243)$ & $1.197(1.138,1.26)$ \\
\hline \multicolumn{9}{|l|}{ Hip fractures } \\
\hline None & $1,027,575$ & 3,570 & $3,618,682.12$ & 0.98655 & 1 (ref.) & 1 (ref.) & 1 (ref.) & 1 (ref.) \\
\hline$<3$ & 233,204 & 605 & $813,626.75$ & 0.74358 & $0.756(0.693,0.824)$ & $0.725(0.662,0.795)$ & $0.759(0.692,0.833)$ & $0.759(0.692,0.832)$ \\
\hline $3-4$ & 95,985 & 294 & $336,810.4$ & 0.87289 & $0.886(0.786,0.998)$ & $0.841(0.742,0.953)$ & $0.833(0.734,0.945)$ & $0.836(0.737,0.948)$ \\
\hline$\geq 5$ & 74,775 & 323 & $267,106.28$ & 1.20926 & $1.221(1.09,1.369)$ & $1.158(1.026,1.307)$ & $1.072(0.948,1.211)$ & $1.085(0.96,1.227)$ \\
\hline \multicolumn{9}{|c|}{ Fractures of limbs (upper arm, forearm, and lower leg) } \\
\hline None & $1,027,575$ & 32,847 & $3,618,682.12$ & 9.07706 & 1 (ref.) & 1 (ref.) & 1 (ref.) & 1 (ref.) \\
\hline$<3$ & 233,204 & 4,833 & $813,626.75$ & 5.94007 & $0.655(0.635,0.675)$ & $1.025(0.993,1.059)$ & $1.031(0.997,1.065)$ & $1.032(0.999,1.067)$ \\
\hline $3-4$ & 95,985 & 1,846 & $336,810.4$ & 5.48083 & $0.605(0.577,0.634)$ & $1.111(1.057,1.168)$ & $1.11(1.056,1.168)$ & $1.116(1.062,1.174)$ \\
\hline$\geq 5$ & 74,775 & 1,599 & $267,106.28$ & 5.98638 & $0.66(0.628,0.694)$ & $1.25(1.185,1.319)$ & $1.237(1.172,1.305)$ & $1.253(1.187,1.322)$ \\
\hline
\end{tabular}

Model 1: unadjusted, Model 2: gender, Model 3: gender, income, diabetes, hypertension, and hyperlipidemia, smoking, physical exercise, body mass index, Model 4: gender, income, diabetes, hypertension, and hyperlipidemia, smoking, physical exercise, body mass index, fracture history. *person-years, tincidence rate per 1,000 years



Figure 3. Risk of fractures according to amount of alcohol intake. *adjusted for gender, income, diabetes, hypertension, and hyperlipidemia, smoking, physical exercise, body mass index, fracture history.

J-shaped association between alcohol consumption and fracture risk remained even in the elderly population $(\geq 66)$. We found that heavy drinkers having the highest (24.6\% greater) and mild drinkers having the lowest (4.5\% less) risk of fracture compared with none drinkers. Similar association was observed for the weekly alcohol consumption frequency.
In addition, the fracture risk was decreased in the lowest daily alcohol consumption ( $<10 \mathrm{~g} /$ day $=5.4 \%)$ group, and the risk became sequentially greater from those drinking $\geq 30 \mathrm{~g} /$ day (15\%) to $\geq 60 \mathrm{~g} /$ day $(47.5 \%)$.

The pathophysiological basis of alcohol consumption and fracture risk having a non-linear relationship is still obscure. Studies repeatedly showed that light to moderate drinking resulted in higher bone mineral density (BMD) and reduced agerelated bone loss. ${ }^{30,31}$ In contrast, heavy alcohol intake was associated negative impact in bone quality, decreased BMD, and higher age-related bone loss. ${ }^{32,33}$ Likewise, light to moderate drinkers were shown to have better health-promoting behaviors such as increased physical activity, social interactions, and a nutritious diet, which will also culminate to reduced agerelated bone loss. ${ }^{34,35}$ In contrast, heavy drinkers tended to make unhealthy lifestyle choices and have higher risk of alcohol-associated disease and altered endocrine signaling, which results in negative impact in bone remodeling. ${ }^{4,36-38}$ Studies also showed that light alcohol drinkers had a lower risk of incident falls than non-drinkers. ${ }^{11}$ In line with this hypothesis, a reverse $U$ shape between physical activity and drinking groups was also ob- 
served in our cohort. The fact that history of fall was more common in none-drinking group could also be an important contributing factor. In the other perspective, large proportion of subjects in non-drinkers might already have been physically too frail to enjoy alcohol consumption. Likewise, non-drinkers were also shorter, had lower weight, and conducted less physical exercise. Thus, the higher risk of fall and fracture in the non-drinker group could have been a result of physically frailty rather than from alcohol abstinence. Further large cohort studies with longitudinal design are needed to clarify this important controversy.

Interestingly, risk pattern of alcohol consumption and fracture differed according to affected bones. For vertebral bones, a similar J-shaped association was noted between drinking group, drinking frequency, and daily alcohol consumption with that of fracture risk. However, this this J-shape was not evident, and the risk tended to increase linearly in limb fracture. Alcohol intake, even in low amount, is known to be associated with impaired judgement and poor motor control resulting in traumatic injury. ${ }^{39-41}$ The poor body coordination might have increased with alcohol consumption intensity which resulted in linear association between alcohol intake and fracture of the limbs. Osteoporosis might have been another important cause because BMI tended to decrease linearly associated with increasing drinking intensity.

In contrast, the fracture risk decrement from mild to moderate drinking was more pronounced for hip fracture, and the risk increment did not show statistical significance even in the severe drinking group. Likewise, there was more than $20 \%$ decrement for those drinking $<10 \mathrm{~g} /$ day and $10-20 \mathrm{~g} /$ day, and the significant increase of hip fracture was only observed for very severe drinkers [those drinking $\geq 60 \mathrm{~g} / \mathrm{day}(\mathrm{aHR}=1.446)$ ]. All the participants in our study were aged 66 , which can be classified as "young-old."42 Unlike fracture of limbs, light trauma may not have resulted in hip fracture in these "young-old" because their osteoporosis might not have been critically severe. In addition, for light to moderate alcohol drinkers, the benefits of alcohol in bone mineral density could have out weighted the risk of fracture occurring from minor traumatic events. In with our hypothesis, risk factors for hip fracture are known to change with age. ${ }^{8}$ Studies suggested that falls and fall- related factors were most predictive of hip fracture in those who are older than $\geq 75$, but in those who are younger. ${ }^{43}$ Likewise, many other studies also showed that hip fractures were increased only in heavy drinking groups. ${ }^{10,13}$

Our study has other strengths. First, we included all people aged 66, a total of 1,431,539 subjects, who received health screening from 2009-2014. Thus, besides having the largest cohort, we were able to prevent selection bias and minimize recruitment setting effect, thereby our results have higher generaliz- ability. By including patients with 66 only, we were also able to completely remove "age" as a potential cofactor and focus on impact of alcohol consumption in the fracture incidence. In addition, we are the first to show that the fracture risk from alcohol intake could be different depending on the affected bones.

This paper also has several limitations. The intake of alcohol was based on a self-reported questionnaire. Thus, reporting bias is an important issue. Osteopenia, osteoporosis, and bone mineral density are all important risk factors of fracture, but we did not include them in the analysis. We were not able to investigate relationship among cause of fracture, fracture sites, and alcohol consumption intensity despite their potential associations. Lastly, association among gender, alcohol preference or type of alcohol, and fracture risk was not addressed.

In conclusion, we showed that there is a J-shaped association between alcohol consumption and risk of total fracture. We further demonstrated that pattern of fracture risk differed depending on the skeletal sites. Vertebra showed a similar Jshaped association between alcohol consumption and fracture risk, but the fracture risk tended to increase linearly for limbs. For hip bones, fracture risk decrement from mild to moderate drinking was more pronounced and risk increment was only noted in very severe drinkers.

\section{Acknowledgments}

This work was supported by the National Research Foundation of Korea (NRF) grant funded by the Korea government (MSIT) (No. 2019R1A2C2009100).

\section{Conflicts of Interest}

The authors have no potential conflicts of interest to disclose.

\section{Author Contributions}

Conceptualization: Sheng-Min Wang, Hyun Kook Lim. Data curation: Hyun Kook Lim. Formal analysis: Hyun Kook Lim, Kyung-Do Han. Funding acquisition: Hyun Kook Lim. Investigation: Yoo Hyun Um, Dong Woo Kang, Nak-Young Kim, Hae-Ran Na. Methodology: Hyun Kook Lim. Project administration: Hyun Kook Lim. Resources: Hyun Kook Lim. Supervision: Chang Uk Lee. Writing_-original draft: Sheng-Min Wang. Writingreview\& editing: Kung-Do Han, Yoo Hyun Um, Dong Woo Kang, NakYoung Kim, Hae-Ran Na.

\section{ORCID iDs}

Sheng-Min Wang https://orcid.org/0000-0003-2521-1413

Kyung-Do Han https://orcid.org/0000-0002-6096-1263

Nak-Young Kim https://orcid.org/0000-0003-0116-6283

Yoo Hyun Um https://orcid.org/0000-0002-3403-4140

Dong Woo Kang https://orcid.org/0000-0003-3289-075X

Hae-Ran Na https://orcid.org/0000-0002-7960-8603

Chang Uk Lee https://orcid.org/0000-0001-6398-7330

Hyun Kook Lim https://orcid.org/0000-0001-8742-3409

\section{REFERENCES}

1. Woolf AD, Akesson K. Preventing fractures in elderly people. BMJ 2003;327:89-95.

2. Kim HY, Ha YC, Kim TY, Cho H, Lee YK, Baek JY, et al. Healthcare 
costs of osteoporotic fracture in Korea: Information from the National Health Insurance Claims Database, 2008-2011. J Bone Metab 2017;24: 125-133.

3. Kim J, Lee E, Kim S, Lee TJ. Economic burden of osteoporotic fracture of the elderly in South Korea: A National Survey. Value Health Reg Issues 2016;9:36-41.

4. Berg KM, Kunins HV, Jackson JL, Nahvi S, Chaudhry A, Harris KA, Jr., et al. Association between alcohol consumption and both osteoporotic fracture and bone density. Am J Med 2008;121:406-418.

5. Kanis JA, Johansson H, Johnell O, Oden A, De Laet C, Eisman JA, et al. Alcohol intake as a risk factor for fracture. Osteoporos Int 2005;16: 737-742.

6. Hippisley-Cox J, Coupland C. Derivation and validation of updated QFracture algorithm to predict risk of osteoporotic fracture in primary care in the United Kingdom: prospective open cohort study. BMJ 2012; 344:e3427.

7. Zhang X, Yu Z, Yu M, Qu X. Alcohol consumption and hip fracture risk. Osteoporos Int 2015;26:531-542.

8. Anpalahan M, Morrison SG, Gibson SJ. Hip fracture risk factors and the discriminability of hip fracture risk vary by age: a case-control study. Geriatr Gerontol Int 2014;14:413-419.

9. Liang W, Chikritzhs T. The effect of age on fracture risk: a populationbased cohort study. J Aging Res 2016;2016:5071438.

10. Felson DT, Kiel DP, Anderson JJ, Kannel WB. Alcohol consumption and hip fractures: the Framingham Study. Am J Epidemiol 1988;128: 1102-1110.

11. Cawthon PM, Harrison SL, Barrett-Connor E, Fink HA, Cauley JA, Lewis CE, et al. Alcohol intake and its relationship with bone mineral density, falls, and fracture risk in older men. J Am Geriatr Soc 2006; 54:1649-1657.

12. Samelson EJ, Hannan MT, Zhang Y, Genant HK, Felson DT, Kiel DP. Incidence and risk factors for vertebral fracture in women and men: 25-year follow-up results from the population-based Framingham study. J Bone Miner Res 2006;21:1207-1214.

13. Mukamal KJ, Robbins JA, Cauley JA, Kern LM, Siscovick DS. Alcohol consumption, bone density, and hip fracture among older adults: the cardiovascular health study. Osteoporos Int 2007;18:593-602.

14. Sogaard AJ, Ranhoff AH, Meyer HE, Omsland TK, Nystad W, Tell GS, et al. The association between alcohol consumption and risk of hip fracture differs by age and gender in Cohort of Norway: a NOREPOS study. Osteoporos Int 2018;29:2457-2467.

15. Pluijm SM, Koes B, de Laet C, Van Schoor NM, Kuchuk NO, Rivadeneira $\mathrm{F}$, et al. A simple risk score for the assessment of absolute fracture risk in general practice based on two longitudinal studies. J Bone Miner Res 2009;24:768-774.

16. Kubo JT, Stefanick ML, Robbins J, Wactawski-Wende J, Cullen MR, Freiberg M, et al. Preference for wine is associated with lower hip fracture incidence in post-menopausal women. BMC Womens Health 2013;13:36

17. Cauley JA, Lui LY, Genant HK, Salamone L, Browner W, Fink HA, et al. Risk factors for severity and type of the hip fracture. J Bone Miner Res 2009;24:943-955.

18. Kim HS, Shin DW, Lee WC, Kim YT, Cho B. National screening program for transitional ages in Korea: a new screening for strengthening primary prevention and follow-up care. J Korean Med Sci 2012;27 Suppl:S70-S75.

19. Seong SC, Kim YY, Park SK, Khang YH, Kim HC, Park JH, et al. Cohort profile: the National Health Insurance Service-National Health Screening Cohort (NHIS-HEALS) in Korea. BMJ Open 2017;7:e016640.

20. Cheol Seong S, Kim YY, Khang YH, Heon Park J, Kang HJ, Lee H, et al. Data resource profile: The National Health Information Database of the National Health Insurance Service in South Korea. Int J Epidemiol 2017;46:799-800.

21. Kalinowski A Humphreys K. Governmental standard drink definitions and low-risk alcohol consumption guidelines in 37 countries. Addiction 2016;111:1293-1298.

22. Kannus P. Preventing osteoporosis, falls, and fractures among elderly people. Promotion of lifelong physical activity is essential. BMJ 1999;
318:205-206.

23. Court-Brown CM, Caesar B. Epidemiology of adult fractures: a review. Injury 2006;37:691-697.

24. Boyle M, Masson S, Anstee QM. The bidirectional impacts of alcohol consumption and the metabolic syndrome: cofactors for progressive fatty liver disease. J Hepatol 2018;68:251-267.

25. Kahl KG, Hillemacher T. The metabolic syndrome in patients with alcohol dependency: current research and clinical implications. Prog Neuropsychopharmacol Biol Psychiatry 2016;70:49-56.

26. Hong M, Ha TH, Lee S, Oh S, Myung W. Clinical correlates of alcohol use disorder in depressed patients with unipolar and bipolar disorder. Psychiatry Investig 2019;16:926-932.

27. Lee J, Chang SJ, Kim H, Kim MH, Ahn JS, Park KC, et al. Prolonged risk of suicide reattempts in patients with alcohol use disorder and acute alcohol use: a register-based follow-up Study (2010-2015). Psychiatry Investig 2019;16:145-153.

28. Klop B, do Rego AT, Cabezas MC. Alcohol and plasma triglycerides. Curr Opin Lipidol 2013;24:321-326.

29. Baraona E, Lieber CS. Alcohol and lipids. Recent Dev Alcohol 1998; 14:97-134.

30. Cauley JA, Fullman RL, Stone KL, Zmuda JM, Bauer DC, BarrettConnor E, et al. Factors associated with the lumbar spine and proximal femur bone mineral density in older men. Osteoporos Int 2005;16: 1525-1537.

31. Felson DT, Zhang Y, Hannan MT, Kannel WB Kiel DP. Alcohol intake and bone mineral density in elderly men and women. The Framingham Study. Am J Epidemiol 1995;142:485-492.

32. Santolaria F, Gonzalez-Reimers E, Perez-Manzano JL, Milena A, Gomez-Rodriguez MA, Gonzalez-Diaz A, et al. Osteopenia assessed by body composition analysis is related to malnutrition in alcoholic patients. Alcohol 2000;22:147-157.

33. Kim MJ, Shim MS, Kim MK, Lee Y, Shin YG, Chung CH, et al. Effect of chronic alcohol ingestion on bone mineral density in males without liver cirrhosis. Korean J Intern Med 2003;18:174-180.

34. Slater MD, Basil MD, Maibach EW. A cluster analysis of alcohol-related attitudes and behaviors in the general population. J Stud Alcohol 1999;60:667-674.

35. Gaddini GW, Turner RT, Grant KA, Iwaniec UT. Alcohol: a simple nutrient with complex actions on bone in the adult skeleton. Alcohol Clin Exp Res 2016;40:657-671.

36. Diez-Ruiz A, Garcia-Saura PL, Garcia-Ruiz P, Gonzalez-Calvin JL, Gallego-Rojo F, Fuchs D. Bone mineral density, bone turnover markers and cytokines in alcohol-induced cirrhosis. Alcohol Alcohol 2010; 45:427-430.

37. Jeong JE, Joo SH, Hahn C, Kim DJ, Kim TS. Gender-specific association between alcohol consumption and stress perception, depressed mood, and suicidal ideation: the 2010-2015 KNHANES. Psychiatry Investig 2019;16:386-396.

38. Won SD, Han C. Efficacy of the life goal-focused brief intervention among patients with alcohol use disorder: a preliminary study. Psychiatry Investig 2018;15:476-483.

39. Kelly KN, Kelly C. Pattern and cause of fractures in patients who abuse alcohol: what should we do about it? Postgrad Med J 2013;89:578-583.

40. Min EJ, Kim SG, Lee JS, Seo B, Jung WY, Huh SY, et al. Difference in cognitive function by first onset age of alcohol induced blackout and its duration. Clin Psychopharmacol Neurosci 2019;17:503-508.

41. Kim EH, Kim MS. An event-related potential study of error-monitoring deficits in female college students who participate in binge drinking. Clin Psychopharmacol Neurosci 2019;17:80-92.

42. Forman DE, Berman AD, McCabe CH, Baim DS, Wei JY. PTCA in the elderly: the "young-old" versus the "old-old". J Am Geriatr Soc 1992;40:19-22.

43. Dargent-Molina P, Douchin MN, Cormier C, Meunier PJ, Breart G, EPIDOS Study Group. Use of clinical risk factors in elderly women with low bone mineral density to identify women at higher risk of hip fracture: The EPIDOS prospective study. Osteoporos Int 2002;13:593599. 